\title{
AQ Term Type
}

National Cancer Institute

\section{Source}

National Cancer Institute. AQ Term Type. NCI Thesaurus. Code C45769.

The $\mathrm{NCl}$ term type designation for an "antiquated disease term". 